\title{
Multiple Intervention in Single Setting: Report on Cases over One Year
}

\author{
Nurun Nahar Fatema \\ Department of Paediatric Cardiology and Paediatrics, Armed forces medical college and Combined \\ Military Hospital, Dhaka
}

\begin{abstract}
Key Words : Congenital heart

disease, Device

closure,

percutaneous

intervention.

Background: Association of various types of congenital lesions in a single patient is a very common finding in congenital heart disease cases. Many such lesions are amenable to nonsurgical interventions in single setting. Such interventions along with surgical intervention are also possible in hybrid laboratories. Here we are reporting on our experience of twelve cases of multiple interventions in the year 2015.

Methods: This is a retrospective review of double or multiple interventions done on cases from January 2015 to December 2015 In Lab aid cardiac hospital and Combined Military Hospital Dhaka. Type of Congenital lesions were identified from chest x-ray, ECG, and colour Doppler Echocardiography and combination of interventions were planned accordingly.

Results: Out of twelve cases, $66.66 \%$ were male and $33.34 \%$ were female. Majority of cases (50\%) were in 4-8 years age group. Most common type of disease combination was Atrial Septal Defect (ASD) with Patient Ductus Arteriosus (PDA). Association of Ventricular Septal Defect (VSD) with PDA was found in $16.67 \%$ cases, combination of PDA with coarctation of aorta was found in $16.67 \%$ cases and combination of ASD and VSD was found in 16.67\% cases. Combination of ASD, VSD, PDA was also found with aortic and pulmonary stenosis in some cases. Outcome of multiple interventions in all the cases were good.

Conclusion: Existence of multiple simple congenital heart lesions is a commonly encountered problem in Pediatric cardiac Practice. Multiple Interventions can be done on these lesions safely. Multiple interventions can be done on complex cases also for life saving purpose. One years experience of multiple intervention reported in this study showed excellent outcome.
\end{abstract}

(Cardiovasc. j. 2016; 9(1): 36-42)

\section{Introduction:}

Congenital heart disease includes many types of lesion which involves septum, valves, vessels, routes etc. Surgical treatment of these defects is well established. As children are the precious member of their family, parents always want to avoid surgery and scar on the chest wall of their kids and remain scared about open heart surgery. Idea of intervention was conceived in this background and researchers are continuously enriching the field of intervention since 1967. First successful Intervention was Rashkind balloon atrial septostomy in 1967 by Dr Rashkind of Philadelphia. Later balloon valvuloplasty and device closures, stenting of vessels and intra cardiac structures were innovated. After intervention of single type for single problems, cardiologist started doing multiple interventions on same patient in single setting spontaneously where these were feasible. First reported double intervention in single setting in Bangladesh was atrial septal defect (ASD) device closure and PDA coil occlusion in 2004 in cath lab of combined Military hospital Dhaka. Here we are reporting twelve cases with various types of multiple interventions in single setting in one year. Most common type of multiple interventions involves multiple holes like ASD, ventricular septal defect (VSD) \& patent ductus arteriosus (PDA) closure. But multiple interventions are performed in complex congenital heart lesions also for example balloon atrial septostomy and PDA stenting in a case of pulmonary atresia with intact interventricular septum (IVS). Multiple Interventions are also performed in the disease of various valves like Aortic or pulmonary stenosis associated with ASD VSD or PDA. Lutembacher

Address of Correspondence: Prof. Nurun Nahar Fatema, Department of Paediatric Cardiology and Paediatrics, Armed forces medical college and Combined Military Hospital, Dhaka, Bangladesh. Email: colfatema@hotmail.com 
syndrome can also be treated by multiple interventions. Some diseases of vessels or tracts are associated with ASD, VSD, or PDA. For example Coarctation of aorta often associated with PDA, VSD etc. Left and Right pulmonary artery stenosis sometime associated with ASD, VSD etc.

\section{Methods:}

Total twelve cases of double Intervention were performed in catheterization laboratory of $\mathrm{CMH}$ Dhaka and Lab aid cardiac hospital from January 2015 to December 2015. This is a retrospective review of the entire papers preserved In the Echocardiography laboratory and cardiac catheterization laboratory of both hospitals along with follow up papers from outpatient clinics. Initial work up of all patients was performed with chest x-ray, ECG and Echocardiography. All the cases were referred case from pediatricians all over the country. Type of congenital heart lesions were identified from work up and combination of interventions were planned in cases where these were feasible. All hard ware which were required for the intervention were arranged prior to procedure.

\section{Procedure:}

All cases were drapped and sedated as per protocol of normal diagnostic cardiac catheterization. Initially diagnosis was confirmed and measurement for Interventions was taken. For ASD device closure, balloon sizing was done in all cases. For VSD device and PDA device closure, LV angiography and aortogram was done to take measurement of holes. About $2 \mathrm{~mm}$ larger than the measurement was the size of the device used. For valvular lesion, ventriculography were performed and stenotic area measured. In pulmonary valve $120 \%$ increament of balloon size was taken for dilatation. In aortic valve 100\% annulus diameter was taken to determine balloon size. For coarctation of aorta, balloon size equal to diameter of aortic arch or descending aorta at the level of diaphragm was used for dilation. All procedures were performed under fluoroscopy and transthoracic Echo guide. Result of procedure was assessed by Echo and fluoroscopic Imaging, pressure measurement and angiography on the basis of requirement of a specific case. All the patients were kept in pediatric cardiac intensive care unit (ICU) for observation of $24 \mathrm{hrs}$. Injection heparin was used in device and stent cases. Tab Asprin was used for 06 month in ASD device, 01 month in VSD device and continuously in PDA stent cases. Before discharge, Echocardiography was performed in all cases. Follow up appointment was given in $1,3,6,12,18$ \& 24 months and yearly there other for 3 years in curative interventions. All the study cases completed first follow up and some of the cases completed $3^{\text {rd }}$ follow up so far. In follow up Chest X-ray, ECG and Echocardiography was performed in all cases.
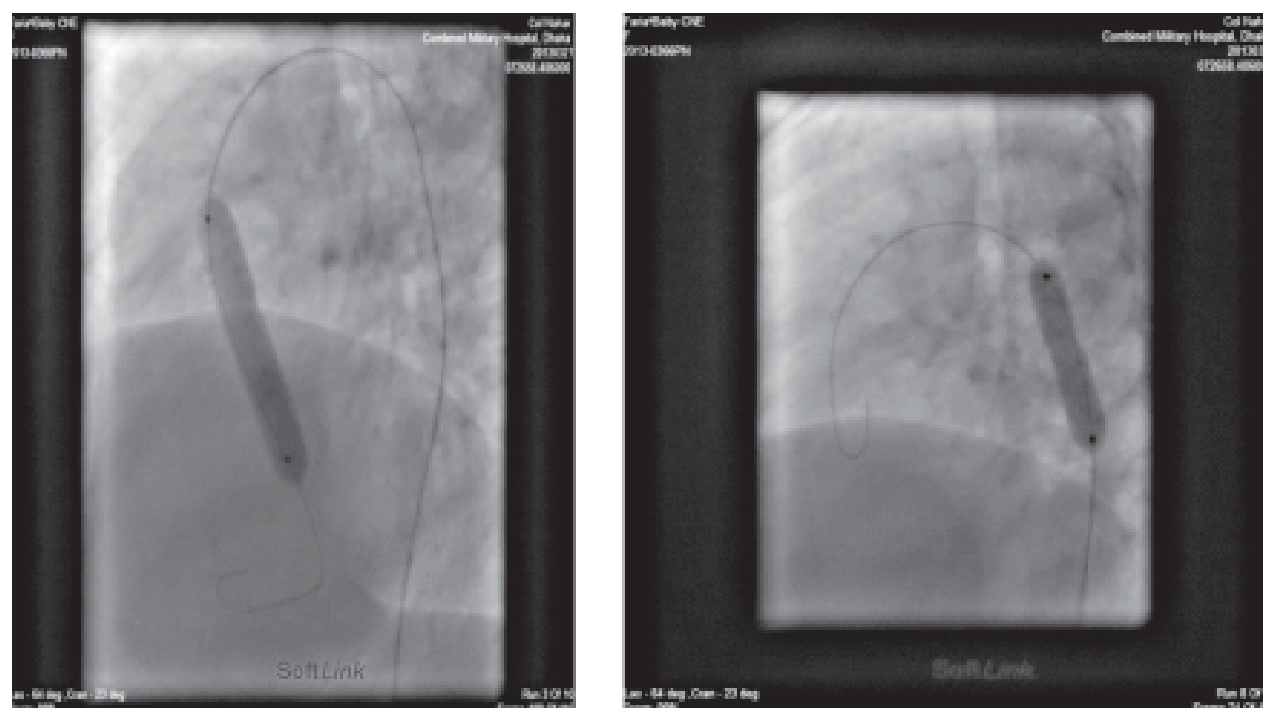

Fig.-1: Showing balloon valvuloplasty for Aortic Stenosis \& balloon coarctoplasty for Coarctation of Aorta . 


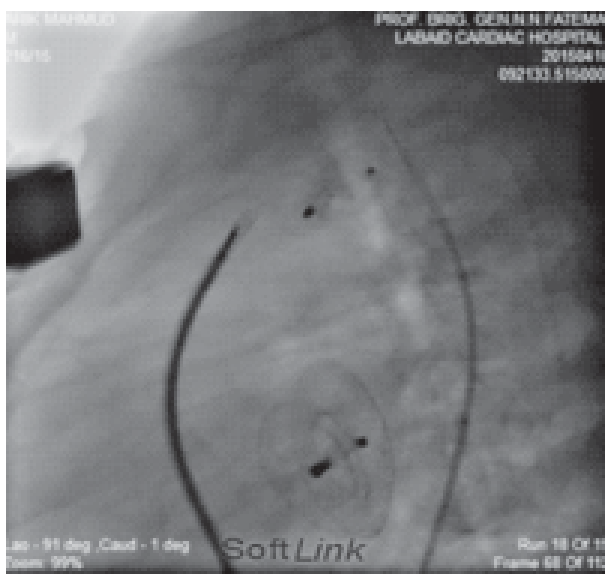

Fig.-2: showing ASD device closure \& PDA device closure in baby $M$, two devices are in situ.

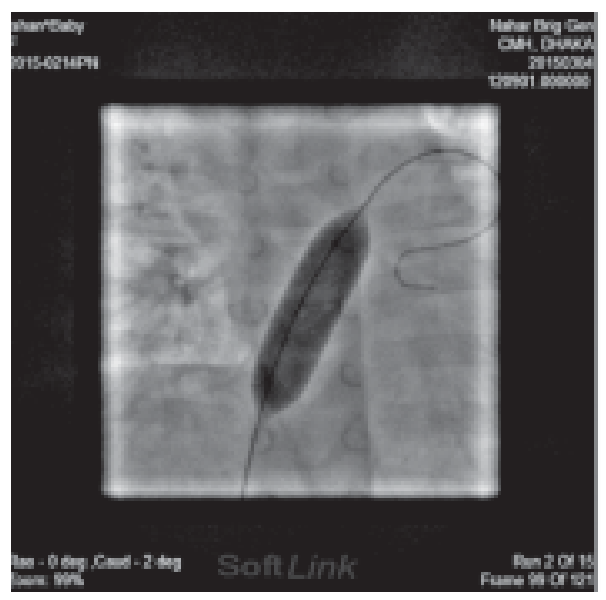

Fig .-4: showing Balloon atrial Septostomy \& RVOT stenting in baby I.

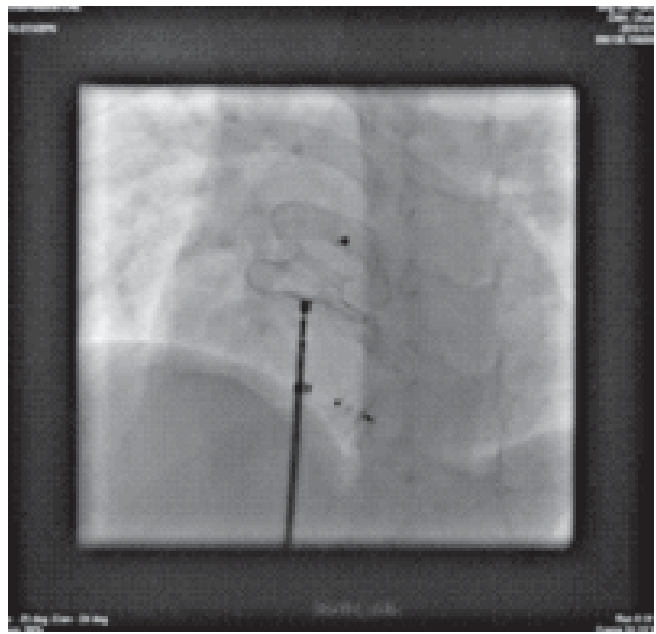

Fig .-5: Showing ASD device closure \& VSD device closure, two devices are in situ.
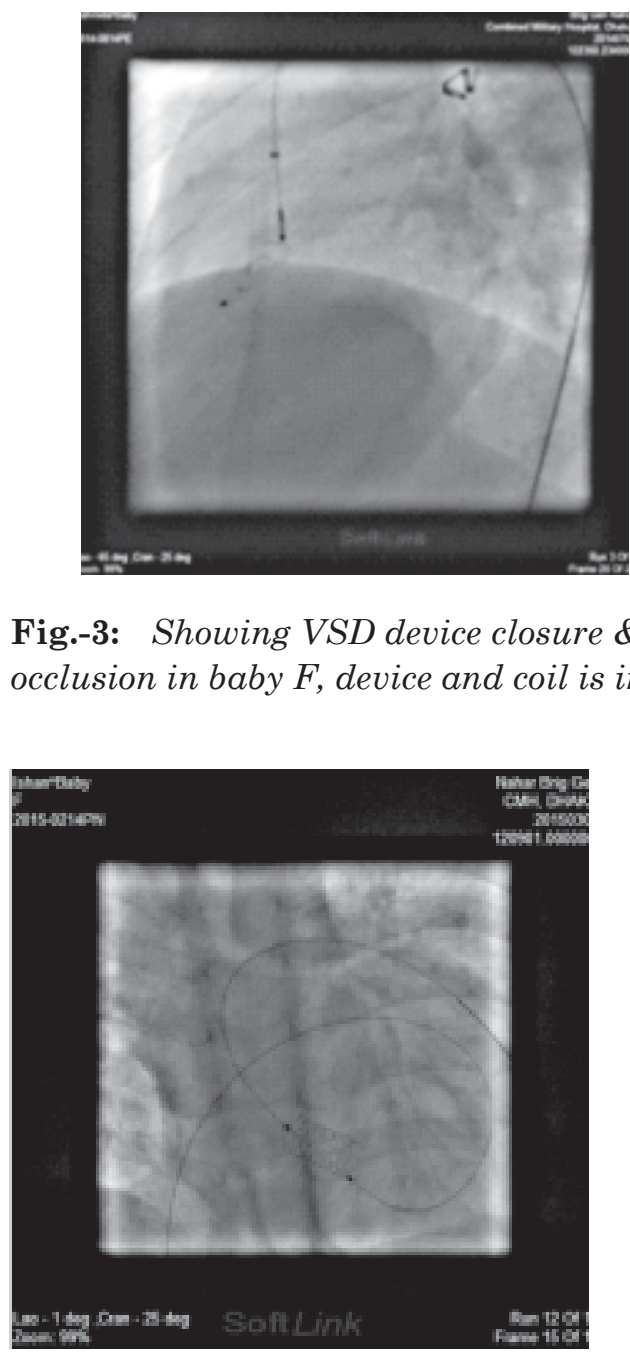

Fig.-3: Showing VSD device closure \& PDA coil occlusion in baby $F$, device and coil is in situ. 


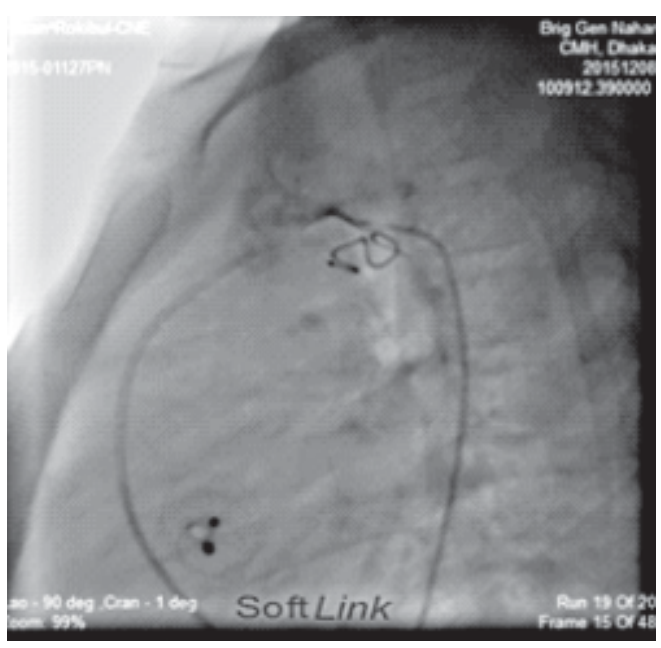

Fig.-7: Showing VSD device closure \& PDA coil occlusion in baby $R$.

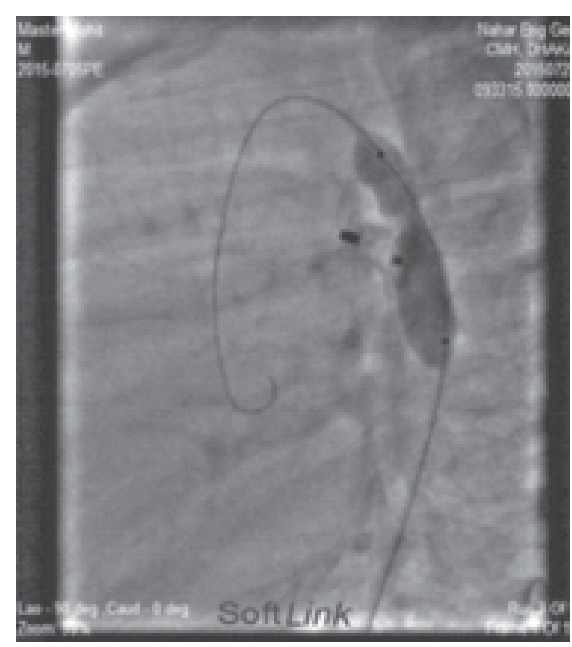

Fig.-9: Showing PDA device closure \& BAP for $C O A$ picture in baby $M$.

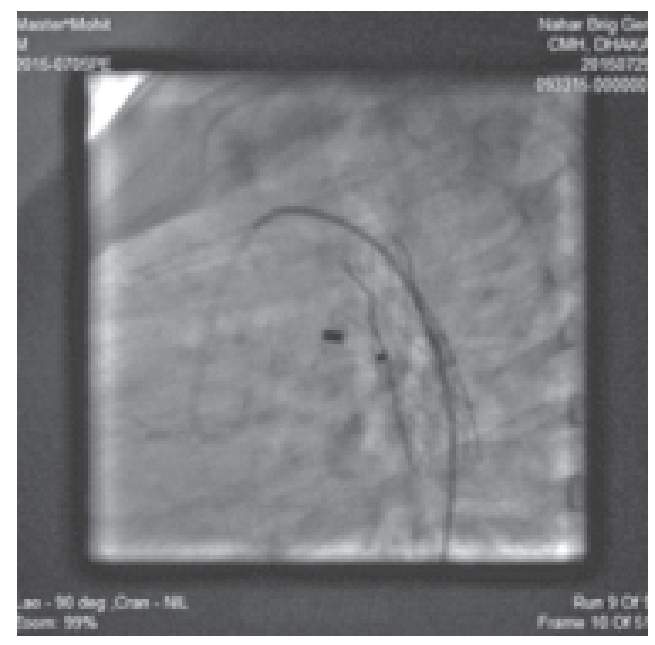

Fig .-8: Showing PDA device closure \& COA stenting in baby $M$, device and stent are in situ.

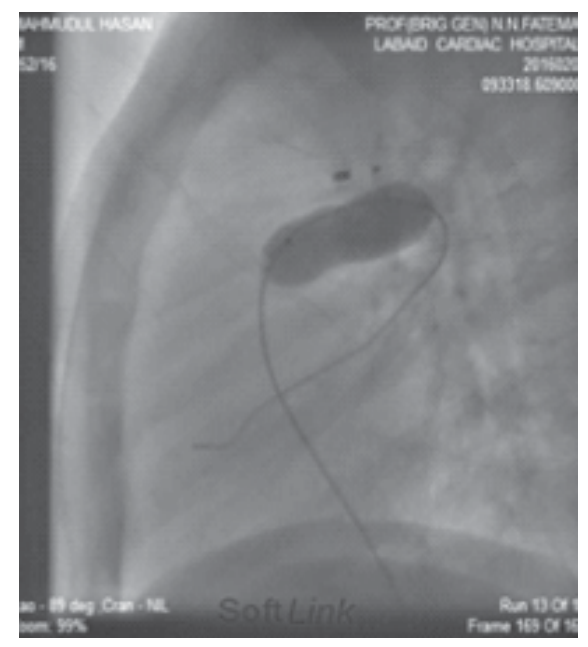

Fig.-10 : Showing PDA device closure \& Balloon valvoplasty for PS picture in baby M. $H$.

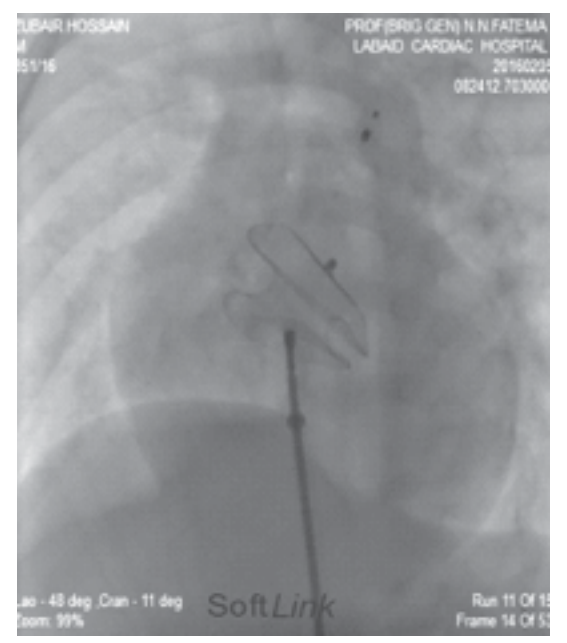

Fig.-11: Showing ASD device closure \& PDA device closure in baby J. 
Results:

Table-I:

Sex distribution of study population.

\begin{tabular}{lcc}
\hline SEX & Total & Percentage \\
\hline Male & 08 & $66.66 \%$ \\
Female & 04 & $33.34 \%$ \\
\hline
\end{tabular}

Table-III

Pattern of disease and types of intervention in study.

\begin{tabular}{llccc}
\hline S/NO & Disease & Total patient & Intervention & Percent(\%) \\
\hline 01 & ASD+ PDA & 3 & 6 & 25 \\
02 & VSD + PDA & 2 & 4 & 16.66 \\
03 & PDA + COA & 2 & 4 & 16.67 \\
04 & ASD + VSD & 2 & 4 & 16.67 \\
05 & PDA + PS & 1 & 2 & 8.34 \\
06 & AS + COA & 1 & 2 & 8.33 \\
07 & Complex CHD & 1 & 2 & 8.33 \\
\hline
\end{tabular}

Table-IV

Demographic profile and outcome of study population.

\begin{tabular}{lcccclc}
\hline S/NO & AGE & SEX & WT & DISEASE & PROCEDURE/INTERVENTION & outcome \\
\hline 01 & $12 \mathrm{Y}$ & Female & $25 \mathrm{Kg}$ & ASD \& PDA & ASD Device Closure \& PDA coil occlusion & Good \\
02 & $04 \mathrm{Y}$ & Male & $10 \mathrm{Kg}$ & PDA \& COA & PDA Device closure \& BAP For COA & Good \\
03 & $08 \mathrm{Y}$ & Male & $18 \mathrm{Kg}$ & VSD \& PDA & VSD Device Closure \& PDA Device Closure & Good \\
04 & $8.5 \mathrm{Y}$ & Male & $18 \mathrm{Kg}$ & ASD \& VSD & ASD Device Closure \& VSD Device Closure & Good \\
05 & $05 \mathrm{Y}$ & Male & $15 \mathrm{Kg}$ & ASD \& PDA & ASD Device Closure \& PDA Device closure & Good \\
06 & $05 \mathrm{Y}$ & Male & $15 \mathrm{Kg}$ & PDA \& PS & PDA Device closure \& BVP FOR PS & Good \\
07 & $18 \mathrm{M}$ & Female & $07 \mathrm{Kg}$ & AS \& COA & Aortic BVP \& BAP For COA & Good \\
08 & $08 \mathrm{Y}$ & Male & $19 \mathrm{Kg}$ & PDA \& COA & PDA Device closure \& BAP For COA & Good \\
09 & $23 \mathrm{M}$ & Male & $09 \mathrm{Kg}$ & TA,DORV,PFO, & PFO Balloon Dilation \& RVOT Stenting & Good \\
10 & $20 \mathrm{M}$ & Male & $10 \mathrm{Kg}$ & ASD \& PDA & ASD Device Closure \& PDA Device closure & Good \\
11 & $6.3 \mathrm{Y}$ & Female & $17 \mathrm{Kg}$ & VSD \& PDA & VSD Device Closure \& PDA coil occlusion & Good \\
12 & $04 \mathrm{Y}$ & Female & $13 \mathrm{Kg}$ & PA,ASD,PDA & PDA stenting \& ASD device closure, ICR for TOF & Good \\
\hline
\end{tabular}




\section{Discussion:}

Dotter and Judkin first introduced therapeutic catheterization when they first dilated a vessel in $1964 .{ }^{1}$ First percutaneous intervention of congenital heart disease in paediatric age group was balloon atrial septostomy, performed in 1966 by Rashkind and miller. ${ }^{2}$ In 1968, Porstman et al first reported trans catheter closure of patent ductus arteriosus. ${ }^{3}$ In 1976, Kings et al first describe the ASD closure in catheterization Laboratory. ${ }^{4}$ First trans catheter pulmonary valvoplasty was reported by Dr. Jean Kan in 1982. ${ }^{5}$ Dr. James Lock et al first reported transcatheter VSD closure in $1988 .{ }^{6}$ Dr. Charles Mullin first introduced endovascular stent in the treatment of congenital heart lesion. ${ }^{7}$ All the above mentioned interventions were innovated for a single specific congenital lesions. But the spectrum of transcatheter procedure rapidly increased in children and adult with increase of expertise, experience of cardiologist and availability of the interventional armamentarium. Suitable small size hardware was also made available from the industrial people by continuous research work. Most of the academic sessions on congenital and structural lesions now concentrate on new device development, choice of appropriate balloons, catheter, sheaths, wires in different situations for a successful outcome. Use of balloon depends on specific intervention intended, for example balloon in balloon $(\mathrm{B} / \mathrm{B})$ is intended for dilation of stent. ${ }^{8}$

Newer devices are coming up continuously to meet the need of specific lesions. This progress allowed many procedures to be performed safely in wide range of centres and cardiologists are able to learn these procedure and technologies by short period of training. Simple congenital lesion often present in a patient in combination. With increasing skill cardiologists are treating more than one congenital lesion by intervention. First ever combined intervention in single setting was performed in Bangladesh was in a patient with ASD and PDA on $27^{\text {th }}$ September 2004. After that many such interventions were done in single setting. Among 70 such interventions since 2004, most common one was device closure of ASD and pulmonary valvuloplasty. ${ }^{9}, 10 \mathrm{In}$ present series we performed twelve intervention in one year where combination of ASD \& PDA was the commonest.

\section{Conclusion:}

Better understanding of anatomy and hemodynamics, increasing skill and knowledge and availability of safe hardware increases the role of pediatric cardiologists in therapeutic interventions of combination lesion or complex lesions in congenital heart disease. Now cases with combination of ASD, VSD, PDA, PS, AS, coarctation of aorta can be dealt with percutaneous interventions with good efficacy and safety. Outcome of present case series of patient in one year will also encourage multiple Intervention in single setting under care of a skilled cardiologist in a good pediatric cardiac center.

\section{Conflict of Interest - None.}

\section{References:}

1. Dotter CT, Judkins MP. Transluminal treatment of arteriosclerotic obstruction. Description of a new technique and a preliminary report of its application. Circulation 1964; 30: 654-670.

2. Raskind WJ, Miller WW. Creation of an atrial Septal defect without thoracotomy. A palliative approach to complete transposition of great arteries. JAMA 1966; 196: 991-992.

3. Porstmann W, Wierry 1, Warnke H. Closure of patient ductus arteriosus without thoracotomy. FortschrGebRontgenstrNuklearmed 1968; 109: 133-148.

4. Wallace S, Giauturco C, Anderson JH. Therapeutic vessel occlusion utilizing still coil technique: Clinical applications. AJR Am J Roentgenol 1976; 127: 381-387.

5. Kan JS, White RI Jr, Mitchell S.E. Percutaneous balloon valvuloplasty: a new method to treat congenital pulmonary valve stenosis. N Eng J Med 1982; 307: 540-542.

6. Lock JE, Block PC, Mckay RG. Transcatheter closure of ventricular Septal defects. Circulation 1988; 78: 361368 .

7. O,Laughlin MP, Perry SB, Lock JE. Use of endovascular stent in congenital heart disease. Circulation 1991; 83: 1923-1939. 
8. Ralf J. Holzer, John P. Cheatham. Therapeutic cardiac catheterization. In: Hugh D Allen, David J Driscoll, Robert E Shaddy, Timothy F. Feltes. Eds. Moss \& Adams Heart disease Infants, children and Adolescents. Philladelphia: Woltens Kluwer/ Lippincott Williams \& Wilkins, 2008: 288-347.

9. NN Fatema, S.M Rahman, MR Karim, M Haque. Double Intervention in single setting in a girl with Atrial Septal defect and patent ductus arteriosus. J Bangladesh Coll Phys Surg 2006; 24(1):34-37.

10. NN Fatema. Short, Intermidiate and long term follow up of device closure of atrial Septal defects (secundum) cases: Thirteen years experience with special reference to complications. Bangladesh Journal of Cardiology 2014; 6 (1-2): 634-639. 